\title{
Research on Two-Level Price-Fluctuation Supply Chain Ordering Strategy Problem
}

\author{
Minchao Zheng, ${ }^{1}$ Zhiqing Meng $\mathbb{D}^{1},{ }^{1}$ and Rui Shen $\mathbb{D}^{2}$ \\ ${ }^{1}$ School of Management, Zhejiang University of Technology, Hangzhou, Zhejiang 310023, China \\ ${ }^{2}$ School of Economics, Zhejiang University of Technology, Hangzhou, Zhejiang 310023, China
}

Correspondence should be addressed to Zhiqing Meng; mengzhiqing@zjut.edu.cn

Received 19 September 2019; Revised 16 January 2020; Accepted 14 February 2020; Published 16 March 2020

Academic Editor: Ricardo López-Ruiz

Copyright (C) 2020 Minchao Zheng et al. This is an open access article distributed under the Creative Commons Attribution License, which permits unrestricted use, distribution, and reproduction in any medium, provided the original work is properly cited.

\begin{abstract}
Uncertainties from retail price-fluctuation sales as well as constraints from suppliers make it difficult for retailers to place accurate orders, which have a great impact on the whole supply chain. Thus, this paper studies a supply chain ordering problem for twolevel price-fluctuation sales and establishes a bilevel programming model by Copula function measuring the correlation between price and demand. The optimal order quantity is derived by transforming the bilevel programming model into a single-level model. An algorithm is given for solving the approximate optimal order quantity for the discrete model, and the convergence of the algorithm is proved. The results show that the approximate optimal order quantity decreases with the increase in the uncertainties of price and demand. Supply chain members should sell more products at the normal level, thereby increasing profits of each member in the supply chain under two-level price-fluctuation sales.
\end{abstract}

\section{Introduction}

With fierce competition caused by product renewal and commodity oversupply, price-fluctuation sales have been widely adopted by retailers. In most concentrated trading markets in China, such as open markets and small commodity markets, retail prices fluctuate with the bargaining power of customers and the purchase volume, so prices of the same commodity are not always the same. In addition, online retail prices change as frequently as those in physical stores $[1,2]$. According to Profitero, an e-commerce analytics company, prices of a quarter of the products sold by Amazon itself change multiple times a day, along with $71 \%$ of products sold by third-party sellers [3]. In addition, to push the sales and catch every dollar revenue, retailers usually take the strategy of a big discount near the end of the sales season, i.e., the second stage of the sales, and make their retail prices fluctuate around another level-the discount price level. So retailers choose two levels for price to fluctuate: at first, they choose the normal price level in the first stage of the sales and then later the discount price level in the second stage of the sales, as it is difficult for retailers to predict the retail price of each transaction in advance $[4,5]$, where retail prices are sort of an uncertain random variable. So it is necessary to study the ordering problems for retailers in twolevel price-fluctuation sales.

In studying ordering problems for retailers, there are lots of similar research studies considering retail price. Some research studies describe multilevel price strategies, where a sale period is usually divided into stages and the retail prices are set for each stage instead of fluctuating. For example, Khouja [6] gave a scenario that discounts are progressively used as long as products remain on the shelf and studied the ordering problem aiming at maximizing the expected profit or maximizing the probability of achieving a target profit. Pang et al. [7] discussed a periodic review model of inventory strategy under dynamic price adjustment and extended it to a multistage inventory system. Federgruen and Heching [8] studied the ordering problem when retail prices change in monotonic decline direction or unknown direction by assuming that retail price is a function of time which satisfies a Markov process, the retailer determines the price 
and the ordering strategy at each stage. Others concern varied price strategies, such as gift coupons and quantity discounts, i.e., the same product is sold at different retail prices [9-11]. For example, $\mathrm{Mu}$ et al. [11] considered a multiple retail price strategy where products are sold at multiple prices simultaneously and proposed an optimal ordering model corresponding to uncertain consumer demands. In sum, no matter what ordering problems are studied, either under a given price strategy or under price adjustments, the retail price is fixed rather than fluctuates at each sales stage, although price changes are taken into account as time flows.

The retailer is definitely a member of a supply chain. Its ordering strategy is affected not only by market conditions and sales strategies but also by suppliers. Some studies have discussed the ordering problem when retail price changes under the setting of a supply chain. For example, Jadidi et al. [12] considered a case where the retail price decreases at the product's midlife and studied the supply chain ordering problem by using Sternberg game theory. In their model, retailers decide the order quantity and price reduction, and suppliers decide the wholesale price. Shah et al. [13] and Widyadana and Wee [14] discussed the supply chain ordering problem with declining retail prices. Shah et al. [13] examined the ordering and coordination problems in a two-echelon supply chain where the supplier decides the wholesale price and the retailer decides the order quantity and the frequency of price reduction. The results showed that the price reduction strategy may improve the profit of the supply chain. Widyadana and Wee [14] discussed the ordering decision and inventory control of the supply chain under the condition that the demand is affected by the price which is steadily decreasing with time. Venegas and Ventura [15] discussed a two-stage ordering problem considering a case that different retail prices are set to the final customer as a reaction to the supplier's discount decisions, where the price and the demand are set to be deterministic variables. Nevertheless, the retail price is fixed. Therefore, the above is not suitable enough for price-fluctuation sales.

As we all know that price and demand are the two major factors that retailer wants to clearly understand to maximize their gain by determining an exact strategy. There are studies on the correlation between price and demand, most in the form of function. For example, Petruzzi and Yao $[16,17]$ summarized two main modes of how price impacts demand: multiplicative mode and additive mode. Tapiero and Kogan $[18,19]$ discussed the ordering problem under the equilibrium market price based on the above two models. In such settings, price is generally assumed to be deterministic which affects demand through a functional relationship with a random term. Such a price is an equilibrium price either determined by market competition or determined by retailers. However, in the real world, demand and price affect each other as a random price and a random demand. To study the above, the joint distribution is used in this paper.
Although it is difficult to calculate the joint distribution of price and demand, the marginal probability distributions of price and demand are easily obtained from historical order data. Furthermore, Copula function provides a way to obtain joint distribution through marginal distributions. Copula function, also known as connection function, was first proposed by Sklar in 1959 [20]. It is mainly used to describe the correlation between random variables, to establish a connection between the marginal distributions, and to establish the joint distribution of multidimensional random variables, thus simplifying the modeling process. Copula function is widely used in the financial field and is an important tool for risk analysis and portfolio investment $[21,22]$. However, few studies have applied Copula function to ordering problems, except $\mathrm{Xu}$ and $\mathrm{Li}$ [23], who applied Copula function to order decision-making and showed Copula function can effectively link random price and random demand together. However, they did not cover supply chain issues nor price strategies.

In summary, the comparison between the above and our research is shown in Table 1.

In ordering decisions, retailers should consider price fluctuations, supplies, and random demand altogether. However, there is no relevant research on supply chain ordering problems with two-level price fluctuations. Thus, this paper mainly discusses an ordering problem in a twoechelon supply chain containing one supplier and one retailer facing two-level price-fluctuation sales and uncertain demand. The followings are the innovations the paper attempts to make:

(i) The extension of the ordering theory, where supply chain ordering problems are extended to a situation where prices fluctuate within a range

(ii) The extension of the ordering theory, where the price fluctuations and the price strategies (i.e., the normal price level strategy and the discount price level strategy) of the retailer in the supply chain are considered together, which is not studied before

(iii) A discrete solution algorithm for solving approximate optimal order quantity

So the focal points of the paper are highlighted in the attempts to study the two-level price-fluctuation supply chain ordering problems. This paper extends the current research on supply chain ordering problems. Since pricefluctuation sales are widespread in the real world, this paper is of great practical significance.

The rest of the paper is organized as follows. Section 2 gives the description and basic hypothesis of the proposed problem. In Section 3, a bilevel programming ordering model under two-level price-fluctuation sales is given, and the optimal order quantity is deduced. In Section 4, a discrete model is established, and an approximate solution algorithm is given for discrete data with the convergence of the algorithm proved. Section 5 carries out numerical 
TABLE 1: Major characteristics of ordering models from selected literature studies.

\begin{tabular}{|c|c|c|c|c|c|c|c|c|c|c|c|c|}
\hline \multirow[t]{2}{*}{ Literature } & \multicolumn{2}{|c|}{$\begin{array}{l}\text { Decision- } \\
\text { maker }\end{array}$} & \multicolumn{3}{|c|}{$\begin{array}{l}\text { The number of } \\
\text { sales stage }\end{array}$} & \multicolumn{4}{|c|}{$\begin{array}{l}\text { The way the retail price } \\
\text { changes in each stage }\end{array}$} & \multicolumn{3}{|c|}{$\begin{array}{c}\text { The correlation between price } \\
\text { and demand }\end{array}$} \\
\hline & $\mathrm{R}$ & $\mathrm{R} \& \mathrm{~S}$ & OS & TS & MS & OUP & NUP & $\mathrm{RP}$ & FR & $\mathrm{AM} / \mathrm{MM}$ & Copula-R & OR \\
\hline Ye and Sun [10] & $\checkmark$ & - & $\checkmark$ & - & - & $\checkmark$ & - & - & - & $\checkmark$ & - & - \\
\hline Mu et al. [11] & $\checkmark$ & - & $\checkmark$ & - & - & - & $\checkmark$ & - & $\checkmark$ & - & - & - \\
\hline Tapiero $[18]$ & $\checkmark$ & - & $\checkmark$ & - & - & - & - & $\checkmark$ & - & - & - & $\checkmark$ \\
\hline Tapiero and Kogan [19] & $\checkmark$ & - & $\checkmark$ & - & - & - & - & $\checkmark$ & - & - & - & $\checkmark$ \\
\hline Khouja et al. [9] & $\checkmark$ & - & - & $\checkmark$ & - & $\checkmark$ & - & - & $\checkmark$ & - & - & - \\
\hline Khouja [6] & $\checkmark$ & - & - & - & $\checkmark$ & $\checkmark$ & - & - & $\checkmark$ & - & - & - \\
\hline Pang et al. [7] & $\checkmark$ & - & - & - & $\checkmark$ & $\checkmark$ & - & - & - & $\checkmark$ & - & - \\
\hline Federgruen and Heching [8] & $\checkmark$ & - & - & - & $\checkmark$ & $\checkmark$ & - & - & - & $\checkmark$ & - & - \\
\hline Venegas and Ventura [15] & - & $\checkmark$ & $\checkmark$ & - & - & - & $\checkmark$ & - & $\checkmark$ & - & - & - \\
\hline Shah et al. [13] & - & $\checkmark$ & - & - & $\checkmark$ & - & $\checkmark$ & - & - & $\checkmark$ & - & - \\
\hline Widyadana and Wee [14] & - & $\checkmark$ & - & - & $\checkmark$ & $\checkmark$ & - & - & - & - & - & $\checkmark$ \\
\hline Jadidi et al. [12] & - & $\checkmark$ & - & $\checkmark$ & - & $\checkmark$ & - & - & - & $\checkmark$ & - & - \\
\hline $\mathrm{Xu}$ and $\mathrm{Li}[23]$ & $\checkmark$ & - & $\checkmark$ & - & - & - & - & $\checkmark$ & - & - & $\checkmark$ & - \\
\hline Our article & - & $\checkmark$ & - & $\checkmark$ & - & - & - & $\checkmark$ & - & - & $\checkmark$ & - \\
\hline
\end{tabular}

Note: R: retailer; R\&S: retailer and supplier; OS: one stage; TS: two stages; MS: multistages; OUP: one unique price, i.e., no change in price; NUP: nonunique price; RP: random change in price; FR: fixed relationship; AM/MM: additive or multiplicative random mode; Copula-R: Copula relationship; OR: other relationship.

simulation experiments, where the influence of uncertainties in price and demand on the ordering strategy and the optimal ordering strategies in different Copula markets are also discussed in this part. Section 6 gives a conclusion.

\section{Problem Description and Hypothesis for Two-Level Price-Fluctuation Ordering Problem}

Since price-fluctuation sales are adopted by many retailers both online and offline where retail prices change over time or vary among clients even at the same moment, this paper studies the two-level price-fluctuation supply chain ordering problem, where retailers adopt normal price level at beginning with retail prices fluctuating in the range $\left[\eta_{1}^{l}, \eta_{1}^{h}\right]$ and adopt a large discount near the end of the sales season in order to push the sales, wherein prices fluctuate in another range $\left[\eta_{2}^{l}, \eta_{2}^{h}\right]$ - the discount level. There are two relationships between these two levels: (1) no overlap between the two and (2) some overlap between the two. Whether the normal price level overlaps the discount price level mainly depends on the discount offered and the extent of price fluctuation at each level. The illustration of two-level pricefluctuation sales is shown in Figures 1(a) and 1(b).

In either case, the statistics of prices are counted at each level which has no impact on our modeling and calculation process. Assume that the lowest retail price regardless of the normal or the discount level is always higher than the wholesale price $w$ from the supplier.

It is well known that demand is almost always uncertain, so the price and the demand here are reasonably assumed to be random variables. Furthermore, the paper takes it into consideration that if products are not sold out at the end of the period, additional costs are required to dispose of them. To make analysis easy, in the study of the two-level price- fluctuation supply chain ordering problem, the following assumptions are taken:

(1) The underorder does not bring additional losses to the retailer, i.e., no shortage cost.

(2) Additional disposal cost is required for the unsold products, which is assumed to be a constant value.

(3) The demand for products at each price level is independent of each other. As customers have different purchase behaviors [24], i.e., some choose to purchase at the normal price level as they do not want to wait while some choose to wait and buy discount products rather than at the normal price level. There is a third type who dynamically adjust their purchase behavior according to the retailer's strategy. Since the sales data at the normal level cover the sales both to the first and to the third type of customers, and the sales data at the discount level relate to both the second and third types of customers, it is not necessary to find the probability distribution for the third type of customers, and the demands at the two price levels as reflected by probability distributions are independent of each other. This assumption is also adopted by some previous studies such as $[25,26]$.

(4) The supplier can satisfy the retailer's order quantity.

(5) In practice, price fluctuations are limited in number, i.e., they are usually of a discrete distribution, and bargaining mechanism and stochastic pricing make common the phenomenon "thousands people, thousands prices." However, to facilitate modeling and to facilitate the study of properties of the model proposed, this paper reasonably assumes that retail price and demand are continuous variables in Section 3.

(6) The marginal probability distributions of both price and demand are continuous. 


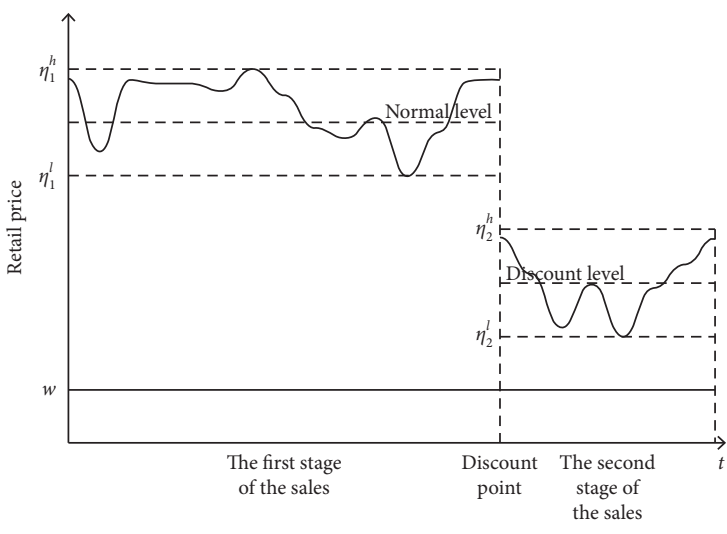

(a)

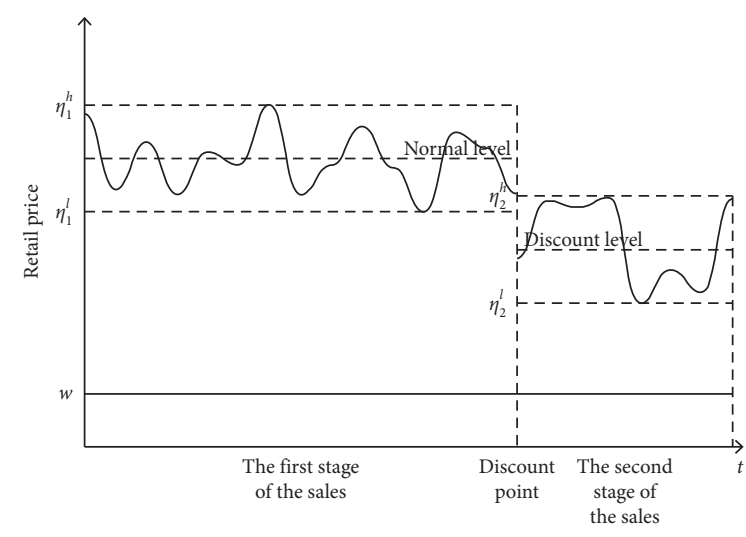

(b)

FIGURE 1: Illustration of two-level price-fluctuation sales: (a) Case 1: no overlap between the two ranges; (b) Case 2: some overlap between the two ranges.

TABle 2: Descriptions of symbols and parameters $(t=1,2)$.

\begin{tabular}{lc}
\hline Symbols and parameters & Descriptions \\
\hline$\eta_{t}, \eta_{t} \in\left[\eta_{t}^{l}, \eta_{t}^{h}\right]$ & Fluctuant retail price \\
$\xi_{t}, \xi_{t} \geq 0$ & Demand \\
$h_{t}\left(\eta_{t}, \xi_{t}\right)$ & Joint probability density function of price and demand \\
$H_{t}\left(\eta_{t}, \xi_{t}\right)$ & Joint probability distribution function of price and demand \\
$g_{t}\left(\eta_{t}\right)$ & Marginal probability density function of price \\
$G_{t}\left(\eta_{t}\right)$ & Marginal probability distribution function of price \\
$f_{t}\left(\xi_{t}\right)$ & Marginal probability density function of demand \\
$F_{t}\left(\xi_{t}\right)$ & Marginal probability distribution function of demand \\
$c_{t}\left(G_{t}\left(\eta_{t}\right), F_{t}\left(\xi_{t}\right)\right)$ & Copula density function \\
$C_{t}\left(G_{t}\left(\eta_{t}\right), F_{t}\left(\xi_{t}\right)\right)$ & Copula distribution function \\
$\pi_{s}$ & Profit of the supplier \\
$\pi_{\mathrm{re}}$ & Profit of the retailer \\
$\pi_{\mathrm{re}}$ & Retailer's profit at normal price level \\
$\pi_{\mathrm{re}}$ & Retailer's profit at discount price level \\
$w$ & Unit wholesale price \\
$c_{h}$ & Unit disposal price \\
$c_{0}$ & Unit production cost of the supplier \\
$Q$ & Order quantity \\
\hline
\end{tabular}

And the descriptions of symbols and parameters are shown in Table 2.

\section{Two-Level Price-Fluctuation Ordering Model in the Supply Chain}

The supply chain system consisting of a supplier and a retailer is considered in the paper, where the wholesale price $w,\left(w \geq c_{0}\right)$ is determined by the supplier, and then the retailer predicts the marginal probability distribution of price and demand at each price level and makes decisions as to the optimal ordering. As per whether the order quantity meets the demand at each price level, the retailer may face three possible sales cases:
Case 1: if the demand is larger than the order quantity at the normal level, i.e., $\xi_{1} \geq Q$, the ordered products are all sold around the normal price, i.e., they are sold at fluctuant prices around the normal price. So there is no need to adopt a discount strategy and no stock left at the end of the period. The retailer's profit in this case is $\left(\eta_{1}-w\right) Q$.

Case 2: if the demand at the normal level is less than the order quantity and the demand at the discount level is larger than the stock left after the sales at the normal level, i.e., $\xi_{1}<Q$ and $\xi_{2} \geq Q-\xi_{1}$, then $\xi_{1}$ products are sold at the normal level, and $Q-\xi_{1}$ products are sold at the discount level, and no stock is left by the end of the sales cycle. The retailer's 
profit, in this case, can be expressed as $\pi_{\mathrm{re}}=\eta_{1} \xi_{1}+\eta_{2}\left(Q-\xi_{1}\right)-w Q$.

Case 3: if the demand at the normal level is less than the order quantity and the demand at the discount level is less than the stock left after the sales at the normal level, i.e., $\xi_{1}<Q$ and $\xi_{2}<Q-\xi_{1}$, then $\xi_{1}$ and $\xi_{2}$ are sold at the normal price level and the discount level, respectively. For products unsold by the end of the sales cycle, an extra cost is needed to dispose of them. Then, the profit of the retailer is expressed as follows:

$$
\pi_{\mathrm{re}}=\eta_{1} \xi_{1}+\eta_{2} \xi_{2}-c_{h}\left(Q-\xi_{1}-\xi_{2}\right)-w Q
$$

From the above analysis, the retailer's total profit is denoted by the following equation:

$$
\pi_{\mathrm{re}}(Q, w)=\pi_{\mathrm{re}_{1}}+\pi_{\mathrm{re}_{2}}-w Q
$$

where the profit at the normal level and discount level for the retailer is expressed as follows accordingly:

$$
\left\{\begin{array}{l}
\pi_{\mathrm{re}_{1}}=\eta_{1} \times \min \left\{\xi_{1}, Q\right\}, \\
\pi_{\mathrm{re}_{2}}=\eta_{2} \times \min \left\{\left(Q-\xi_{1}\right)^{+}, \xi_{2}\right\}-c_{h}\left(Q-\xi_{1}-\xi_{2}\right)^{+},
\end{array}\right.
$$

where $(a)^{+}=\max \{a, 0\}$, and if $\xi_{1}<Q, \pi_{\mathrm{re}_{2}}$ no longer exists.

For the supplier, when the retailer's order quantity is $Q$, the supplier decides within a certain range the optimal wholesale price $w^{*}$, so as to maximize the profit $\pi_{s}\left(w^{*}\right)$, expressed as follows:

$$
\pi_{s}(w)=\left(w-c_{0}\right) Q
$$

To solve the supply chain optimal ordering problem, a bilevel programming model (P1) is presented with the aim of maximizing the expected profit of the supplier and the retailer:

$$
\begin{aligned}
& \text { (P1) } \max \pi_{s}(Q, w)=\left(w-c_{0}\right) Q \\
& \text { s.t. } w \geq c_{0} \text {, }
\end{aligned}
$$

$Q$ is the optimal solution for the retailer in lower-level programming:

$$
\begin{array}{ll}
\max & E\left[\pi_{\mathrm{re}}(Q, w)\right]=E\left(\pi_{\mathrm{re}_{1}}\right)+E\left(\pi_{\mathrm{re}_{2}}\right)-w Q \\
\text { s.t. } & Q \geq 0 .
\end{array}
$$

In the calculation of the retailer's expected profit, it is difficult to obtain the joint distributions $h_{t}\left(\eta_{t}, \xi_{t}\right), t=1,2$ of price and demand in practice, but it is easy to get the marginal probability distributions of price and demand through historical order statistics. Xu and Li [23] showed that Copula function can effectively change the marginal probability distributions of price and demand into the joint distribution. According to Sklar theorem [20], when the joint probability distribution function of twodimensional random variables $x_{1}, x_{2}$ is $P\left(x_{1}, x_{2}\right)$, and the marginal probability distribution of each random variable is $P_{1}(\cdot), P_{2}(\cdot)$, respectively, and all of them are continuous functions, there exists a unique Copula function $C(.,$.$) satisfying the following equation:$

$$
P\left(x_{1}, x_{2}\right)=C\left(P_{1}\left(x_{1}\right), P_{2}\left(x_{2}\right)\right) \text {. }
$$

Therefore, under the assumption that the marginal distribution functions of demand and price $F_{t}(\cdot), t=1,2$, $G_{t}(\cdot), t=1,2$ are continuous, the joint probability distribution functions $H_{t}\left(\eta_{t}, \xi_{t}\right), t=1,2$ of $\xi_{t}$ and $\eta_{t}, t=1,2$ can be uniquely determined if the Copula correlations between them are obtained (please refer to Section 5 for how to select Copula function and how to test it). Assume that $F_{t}\left(\xi_{t}\right)=0,\left(\forall \xi_{t} \in(-\infty, 0]\right)$, and $F_{t}(+\infty)=1$, the price-fluctuation interval of each level is $\left[\eta_{t}^{l}, \eta_{t}^{h}\right], t=1,2$. When Copula functions between price and demand $C_{t}\left(G_{t}\left(\eta_{t}\right), F_{t}\left(\xi_{t}\right)\right)$ are given, and if two Copula functions are both differentiable, the Copula density functions $c_{t}\left(G_{t}\left(\eta_{t}\right), F_{t}\left(\xi_{t}\right)\right)$ are obtained:

$$
c_{t}\left(u_{1}, u_{2}\right)=\frac{\partial^{2} C_{t}\left(u_{1}, u_{2}\right)}{\partial u_{1} \partial u_{2}}
$$

where $u_{1}=G_{t}\left(\eta_{t}\right)$ and $u_{2}=F_{t}\left(\xi_{t}\right)$. The joint probability density functions of price and demand are calculated by the following equation:

$$
h_{t}\left(\eta_{t}, \xi_{t}\right)=c_{t}\left(G_{t}\left(\eta_{t}\right), F_{t}\left(\xi_{t}\right)\right) g_{t}\left(\eta_{t}\right) f_{t}\left(\xi_{t}\right), \quad t=1,2 .
$$

Then, the expected profit of the retailer is expressed via Copula measure. Therefore, a two-level price-fluctuation supply chain ordering model with Copula correlation is established:

$$
\begin{array}{ll}
\text { (P2) } \quad \max & \pi_{s}(Q, w)=\left(w-c_{0}\right) Q \\
\text { s.t. } & w \geq c_{0},
\end{array}
$$

$Q$ is the optimal solution for the retailer in lower-level programming:

$$
\begin{array}{ll}
\max & E_{\text {Copula }}\left[\pi_{r e}(Q, w)\right] \\
\text { s.t. } & Q \geq 0 .
\end{array}
$$

The expected profit of the retailer in the lower-level is expressed by the following equation: 


$$
\begin{aligned}
E_{\text {Copula }}\left[\pi_{\text {re }}(Q, w)\right]= & E_{\text {Copula }}\left(\pi_{\mathrm{re}_{1}}\right)+E_{\text {Copula }}\left(\pi_{\mathrm{re}_{2}}\right)-w Q \\
= & \int_{\eta_{1}^{l}}^{\eta_{1}^{h}} \int_{Q}^{+\infty} \eta_{1} Q c_{1}\left(G_{1}\left(\eta_{1}\right), F_{1}\left(\xi_{1}\right)\right) g_{1}\left(\eta_{1}\right) f_{1}\left(\xi_{1}\right) \mathrm{d} \xi_{1} \mathrm{~d} \eta_{1} \\
& +\int_{\eta_{1}^{l}}^{\eta_{1}^{h}} \int_{0}^{\mathrm{Q}} \eta_{1} \xi_{1} c_{1}\left(G_{1}\left(\eta_{1}\right), F_{1}\left(\xi_{1}\right)\right) g_{1}\left(\eta_{1}\right) f_{1}\left(\xi_{1}\right) \mathrm{d} \xi_{1} \mathrm{~d} \eta_{1} \\
& +\int_{0}^{\mathrm{Q}} f_{1}\left(\xi_{1}\right) \int_{\eta_{2}^{l}}^{\eta_{2}^{h}} \int_{\mathrm{Q}-\xi_{1}}^{+\infty} \eta_{2}\left(Q-\xi_{1}\right) c_{2}\left(G_{2}\left(\eta_{2}\right), F_{2}\left(\xi_{2}\right)\right) g_{2}\left(\eta_{2}\right) f_{2}\left(\xi_{2}\right) \mathrm{d} \xi_{2} \mathrm{~d} \eta_{2} \mathrm{~d} \xi_{1} \\
& +\int_{0}^{Q} f_{1}\left(\xi_{1}\right) \int_{\eta_{2}^{l}}^{\eta_{2}^{h}} \int_{0}^{\mathrm{Q}-\xi_{1}} \eta_{2} \xi_{2} c_{2}\left(G_{2}\left(\eta_{2}\right), F_{2}\left(\xi_{2}\right)\right) g_{2}\left(\eta_{2}\right) f_{2}\left(\xi_{2}\right) \mathrm{d} \xi_{2} \mathrm{~d} \eta_{2} \mathrm{~d} \xi_{1} \\
& -\int_{0}^{Q} f_{1}\left(\xi_{1}\right) \int_{\eta_{2}^{l}}^{\eta_{2}^{h}} \int_{0}^{\mathrm{Q}-\xi_{1}} c_{h}\left(Q-\xi_{1}-\xi_{2}\right) c_{2}\left(G_{2}\left(\eta_{2}\right), F_{2}\left(\xi_{2}\right)\right) g_{2}\left(\eta_{2}\right) f_{2}\left(\xi_{2}\right) \mathrm{d} \xi_{2} \mathrm{~d} \eta_{2} \mathrm{~d} \xi_{1} \\
& -w Q .
\end{aligned}
$$

The optimal ordering quantity of the retailer at a given wholesale price is obtained through Theorem 1 .

Theorem 1. In the lower level of the model (P2), the wholesale price $w$ of the supplier and the Copula functions are given. If the marginal distributions of price and demand are continuous, then the expected profit $E_{\text {Copula }}\left[\pi_{r e}(Q, w)\right]$ is strictly concave w.r.t. $Q$, and the optimal order quantity $Q^{*}$ is determined by the unique solution to the first-order condition of $\left(d E_{\text {Copula }}\left[\pi_{r e}(Q, w)\right]\right) / d Q$ and satisfies the following condition:

$$
\begin{aligned}
& {\left[E\left(\eta_{1}\right)-\int_{\eta_{1}^{l}}^{\eta_{1}^{h}} \eta_{1} S_{1}\left(\eta_{1}, Q^{*}\right) g_{1}\left(\eta_{1}\right) \mathrm{d} \eta_{1}\right]+E\left(\eta_{2}\right) F_{1}\left(Q^{*}\right)} \\
& -\left[\int_{0}^{Q^{*}} f_{1}\left(\xi_{1}\right) \int_{\eta_{2}^{l}}^{\eta_{2}^{h}}\left(\eta_{2}+c_{h}\right) S_{2}\left(\eta_{2}, Q^{*}-\xi_{1}\right) g_{2}\right. \\
& \left.\cdot\left(\eta_{2}\right) \mathrm{d} \eta_{2} \mathrm{~d} \xi_{1}\right]=w
\end{aligned}
$$

where $E\left(\eta_{1}\right), E\left(\eta_{2}\right)$ are the expected values of fluctuant prices at the normal and the discount levels, respectively; $S_{1}(\cdot)$ and $S_{2}(\cdot)$ are denoted by the following equations:

$$
\begin{gathered}
S_{1}\left(\eta_{1}, Q^{*}\right)=\int_{0}^{Q^{*}} c_{1}\left(G_{1}\left(\eta_{1}\right), F_{1}\left(\xi_{1}\right)\right) f_{1}\left(\xi_{1}\right) \mathrm{d} \xi_{1}, \\
S_{2}\left(\eta_{2}, Q^{*}-\xi_{1}\right)=\int_{0}^{Q^{*}-\xi_{1}} c_{2}\left(G_{2}\left(\eta_{2}\right), F_{2}\left(\xi_{2}\right)\right) f_{2}\left(\xi_{2}\right) \mathrm{d} \xi_{2} .
\end{gathered}
$$

Proof of Theorem 1. As $c_{t}(\cdot), G_{t}(\cdot)$, and $F_{t}(\cdot)$ are continuous, then the variable limit integral function $E_{\text {Copula }}\left[\pi_{\text {re }}(Q, w)\right]$ is continuous and derivable for $Q \geq 0$. Using Newton-Leibniz's formula, the first-order condition of $E_{\text {Copula }}\left[\pi_{\text {re }}(Q, w)\right]$ w.r.t. $Q$ gives

$$
\begin{aligned}
\frac{\mathrm{d} E_{\text {Copula }}\left[\pi_{\mathrm{re}}(Q, w)\right]}{\mathrm{d} Q}= & \int_{\eta_{1}^{l}}^{\eta_{1}^{h}} \int_{Q}^{+\infty} \eta_{1} c_{1}\left(G_{1}\left(\eta_{1}\right), F_{1}\left(\xi_{1}\right)\right) g_{1}\left(\eta_{1}\right) f_{1}\left(\xi_{1}\right) \mathrm{d} \xi_{1} \mathrm{~d} \eta_{1} \\
& +\int_{0}^{Q} f_{1}\left(\xi_{1}\right) \int_{\eta_{2}^{l}}^{\eta_{2}^{h}} \eta_{2}\left(Q-\xi_{1}\right) c_{2}\left(G_{2}\left(\eta_{2}\right), F_{2}\left(Q-\xi_{1}\right)\right) g_{2}\left(\eta_{2}\right) f_{2}\left(Q-\xi_{1}\right) \mathrm{d} \eta_{2} \mathrm{~d} \xi_{1} \\
& -\int_{0}^{Q} f_{1}\left(\xi_{1}\right) \int_{\eta_{2}^{l}}^{\eta_{2}^{h}} \int_{0}^{Q-\xi_{1}} c_{h} c_{2}\left(G_{2}\left(\eta_{2}\right), F_{2}\left(\xi_{2}\right)\right) g_{2}\left(\eta_{2}\right) f_{2}\left(\xi_{2}\right) \mathrm{d} \xi_{2} \mathrm{~d} \eta_{2} \mathrm{~d} \xi_{1} \\
& -\int_{0}^{Q} f_{1}\left(\xi_{1}\right) \int_{\eta_{2}^{l}}^{\eta_{2}^{h}} \eta_{2}\left(Q-\xi_{1}\right) c_{2}\left(G_{2}\left(\eta_{2}\right), F_{2}\left(Q-\xi_{1}\right)\right) g_{2}\left(\eta_{2}\right) f_{2}\left(Q-\xi_{1}\right) \mathrm{d} \eta_{2} \mathrm{~d} \xi_{1} \\
& +\int_{0}^{Q} f_{1}\left(\xi_{1}\right) \int_{\eta_{2}^{l}}^{\eta_{2}^{h}} \int_{Q-\xi_{1}}^{+\infty} \eta_{2} c_{2}\left(G_{2}\left(\eta_{2}\right), F_{2}\left(\xi_{2}\right)\right) g_{2}\left(\eta_{2}\right) f_{2}\left(\xi_{2}\right) \mathrm{d} \xi_{2} \mathrm{~d} \eta_{2} \mathrm{~d} \xi_{1} \\
& -w .
\end{aligned}
$$


Via simplification, we have

$$
\begin{aligned}
\frac{\mathrm{d} E_{\text {Copula }}\left[\pi_{\mathrm{re}}(Q, w)\right]}{\mathrm{d} Q}= & \int_{\eta_{1}^{l}}^{\eta_{1}^{h}} \int_{Q}^{+\infty} \eta_{1} c_{1}\left(G_{1}\left(\eta_{1}\right), F_{1}\left(\xi_{1}\right)\right) g_{1}\left(\eta_{1}\right) f_{1}\left(\xi_{1}\right) \mathrm{d} \xi_{1} \mathrm{~d} \eta_{1} \\
& +\int_{0}^{Q} f_{1}\left(\xi_{1}\right) \int_{\eta_{2}^{l}}^{\eta_{2}^{h}} \int_{Q-\xi_{1}}^{+\infty} \eta_{2} c_{2}\left(G_{2}\left(\eta_{2}\right), F_{2}\left(\xi_{2}\right)\right) g_{2}\left(\eta_{2}\right) f_{2}\left(\xi_{2}\right) \mathrm{d} \xi_{2} \mathrm{~d} \eta_{2} \mathrm{~d} \xi_{1} \\
& -\int_{0}^{Q} f_{1}\left(\xi_{1}\right) \int_{\eta_{2}^{l}}^{\eta_{2}^{h}} \int_{0}^{Q-\xi_{1}} c_{h} c_{2}\left(G_{2}\left(\eta_{2}\right), F_{2}\left(\xi_{2}\right)\right) g_{2}\left(\eta_{2}\right) f_{2}\left(\xi_{2}\right) \mathrm{d} \xi_{2} \mathrm{~d} \eta_{2} \mathrm{~d} \xi_{1} \\
& -w .
\end{aligned}
$$

Then, (13) holds for $\left(\mathrm{d} E_{\text {Copula }}\left[\pi_{\mathrm{re}}(Q, w)\right]\right) / \mathrm{d} Q=0$.

The second derivative of $E_{\text {Copula }}\left[\pi_{\text {re }}(Q, w)\right]$ is calculated. The derivative of the first term of formula (16) w.r.t. $Q$ is given by

$$
-\int_{\eta_{1}^{l}}^{\eta_{1}^{h}} \eta_{1} c_{1}\left(G_{1}\left(\eta_{1}\right), F_{1}(Q)\right) g_{1}\left(\eta_{1}\right) f_{1}(Q) \mathrm{d} \eta_{1} .
$$

The derivative of the second term gives

$$
\begin{aligned}
& f_{1}(Q) \int_{\eta_{2}^{l}}^{\eta_{2}^{h}} \int_{0}^{+\infty} \eta_{2} c_{2}\left(G_{2}\left(\eta_{2}\right), F_{2}\left(\xi_{2}\right)\right) g_{2}\left(\eta_{2}\right) f_{2}\left(\xi_{2}\right) \mathrm{d} \xi_{2} \mathrm{~d} \eta_{2} \\
& \quad-f_{1}(0) \int_{\eta_{2}^{l}}^{\eta_{2}^{h}} \int_{Q}^{+\infty} \eta_{2} c_{2}\left(G_{2}\left(\eta_{2}\right), F_{2}\left(\xi_{2}\right)\right) g_{2}\left(\eta_{2}\right) f_{2}\left(\xi_{2}\right) \mathrm{d} \xi_{2} \mathrm{~d} \eta_{2} \\
& \quad-\int_{0}^{Q} \int_{\eta_{2}^{l}}^{\eta_{2}^{h}} \eta_{2} c_{2}\left(G_{2}\left(\eta_{2}\right), F_{2}\left(Q-\xi_{1}\right)\right) f_{2}\left(Q-\xi_{1}\right) g_{2} \\
& \cdot\left(\eta_{2}\right) f_{1}\left(\xi_{1}\right) \mathrm{d} \eta_{2} \mathrm{~d} \xi_{1} .
\end{aligned}
$$

The derivative of the third term gives

$$
\begin{aligned}
& -f_{1}(0) \int_{\eta_{2}^{l}}^{\eta_{2}^{h}} \int_{0}^{Q} c_{h} c_{2}\left(G_{2}\left(\eta_{2}\right), F_{2}\left(\xi_{2}\right)\right) f_{2}\left(\xi_{2}\right) g_{2}\left(\eta_{2}\right) f_{2}\left(\xi_{2}\right) \mathrm{d} \xi_{2} \mathrm{~d} \eta_{2} \\
& -\int_{0}^{Q} \int_{\eta_{2}^{l}}^{\eta_{2}^{h}} c_{h} c_{2}\left(G_{2}\left(\eta_{2}\right), F_{2}\left(Q-\xi_{1}\right)\right) f_{2}\left(Q-\xi_{1}\right) g_{2}\left(\eta_{2}\right) f_{1}\left(\xi_{1}\right) \mathrm{d} \eta_{2} \mathrm{~d} \xi_{1} .
\end{aligned}
$$

Since the probability of a continuous random variable at a certain point approximately equals to zero, we have $\left(\mathrm{d}^{2} E_{\text {Copula }}\left[\pi_{\mathrm{re}}(\mathrm{Q}, w)\right]\right) / \mathrm{dQ}^{2}$ by adding the above three:

$$
\begin{aligned}
& \frac{\left(\mathrm{d}^{2} E_{\text {Copula }}\left[\pi_{\mathrm{re}}(Q, w)\right]\right)}{\mathrm{d} Q^{2}} \\
& =-\int_{\eta_{1}^{h}}^{\eta_{1}^{h}} \eta_{1} c_{1}\left(G_{1}\left(\eta_{1}\right), F_{1}(Q)\right) f_{1}(Q) g_{1}\left(\eta_{1}\right) \mathrm{d} \eta_{1} \\
& -\int_{0}^{Q} f_{1}\left(\xi_{1}\right) \int_{\eta_{2}^{l}}^{\eta_{2}^{h}}\left(\eta_{2}+c_{h}\right) c_{2}\left(G_{2}\left(\eta_{2}\right), F_{2}\left(Q-\xi_{1}\right)\right) \\
& \cdot f_{2}\left(Q-\xi_{1}\right) g_{2}\left(\eta_{2}\right) \mathrm{d} \eta_{2} \mathrm{~d} \xi_{1} .
\end{aligned}
$$

We have $\left(\left(\mathrm{d}^{2} E_{\text {Copula }}\left[\pi_{\mathrm{re}}(Q, w)\right]\right) / \mathrm{d}^{2}\right)<0$ for $Q>0$. Hence, $E_{\text {Copula }}\left[\pi_{\text {re }}(Q, w)\right]$ is strictly concave, and $Q^{*}$ is the only optimal solution for the retailer in the lower-level programming at given $w$.

According to Theorem 1, (P2) can be transformed into the single-level model (P3):

$$
\begin{array}{ll}
\max & \pi_{s}(w, Q)=\left(w-c_{0}\right) Q \\
\text { s.t. } & w \geq c_{0}, \\
\text { (P3) } & E\left(\eta_{1}\right)-\int_{\eta_{1}^{l}}^{\eta_{1}^{h}} \eta_{1} S_{1}\left(\eta_{1}, Q\right) g_{1}\left(\eta_{1}\right) \mathrm{d} \eta_{1}+E\left(\eta_{2}\right) F_{1}(Q) \\
& -\int_{0}^{Q} f_{1}\left(\xi_{1}\right) \int_{\eta_{2}^{l}}^{\eta_{2}^{h}}\left(\eta_{2}+c_{h}\right) S_{2}\left(\eta_{2}, Q-\xi_{1}\right) g_{2}\left(\eta_{2}\right) \mathrm{d} \eta_{2} \mathrm{~d} \xi_{1}=w .
\end{array}
$$

Corollary 1. In two-level price-fluctuation sales, the optimal order quantity $Q^{*}$ of the retailer in lower-level programming decreases with the increase of the wholesale price $w$ offered by the supplier.

Proof of Corollary 1. Derive the left and the right parts of equation (13) w.r.t. $w$ : 


$$
\begin{aligned}
& -Q^{\prime}(w) \int_{\eta_{1}^{h}}^{\eta_{1}^{h}} \eta_{1} c_{1}\left(G_{1}\left(\eta_{1}\right), F_{1}(Q)\right) g_{1}\left(\eta_{1}\right) f_{1}(Q) \mathrm{d} \eta_{1} \\
& -Q^{\prime}(w) \int_{0}^{Q} \int_{\eta_{2}^{l}}^{\eta_{2}^{h}} \eta_{2} c_{2}\left(G_{2}\left(\eta_{2}\right), F_{2}\left(Q-\xi_{1}\right)\right) f_{2}\left(Q-\xi_{1}\right) g_{2}\left(\eta_{2}\right) f_{1}\left(\xi_{1}\right) \mathrm{d} \eta_{2} \mathrm{~d} \xi_{1} \\
& -Q^{\prime}(w) \int_{0}^{Q} \int_{\eta_{2}^{l}}^{\eta_{2}^{h}} c_{h} c_{2}\left(G_{2}\left(\eta_{2}\right), F_{2}\left(Q-\xi_{1}\right)\right) f_{2}\left(Q-\xi_{1}\right) g_{2}\left(\eta_{2}\right) f_{1}\left(\xi_{1}\right) \mathrm{d} \eta_{2} \mathrm{~d} \xi_{1}-1=0 .
\end{aligned}
$$

Via simplification, we have

$\mathrm{Q}^{\prime}(w)=\frac{-1}{\int_{\eta_{1}^{h}}^{\eta_{1}^{h}} \eta_{1} c_{1}\left(G_{1}\left(\eta_{1}\right), F_{1}(Q)\right) g_{1}\left(\eta_{1}\right) f_{1}(Q) \mathrm{d} \eta_{1}+\int_{0}^{Q} \int_{\eta_{2}^{\prime}}^{\eta_{2}^{h}} \eta_{2} c_{2}\left(G_{2}\left(\eta_{2}\right), F_{2}\left(Q-\xi_{1}\right)\right) f_{2}\left(Q-\xi_{1}\right) g_{2}\left(\eta_{2}\right) f_{1}\left(\xi_{1}\right) \mathrm{d} \eta_{2} \mathrm{~d} \xi_{1}+\int_{0}^{Q} \int_{\eta_{2}^{\prime}}^{\eta_{2}^{h}} c_{h} c_{2}\left(G_{2}\left(\eta_{2}\right), F_{2}\left(Q-\xi_{1}\right)\right) f_{2}\left(Q-\xi_{1}\right) g_{2}\left(\eta_{2}\right) f_{1}\left(\xi_{1}\right) \mathrm{d} \eta_{2} \mathrm{~d} \xi_{1}}$.

Obviously, $Q^{\prime}(w)<0$ for $w>c_{0}$. Therefore, the order quantity decreases with the increase in wholesale prices.

In a special case where the price fluctuation does not affect demand, i.e., when price and demand are independent of each other, the Copula function is expressed as the product of the corresponding marginal distributions, i.e., $C_{t}\left(G_{t}\left(\eta_{t}\right), F_{t}\left(\xi_{t}\right)\right)=G_{t}\left(\eta_{t}\right) \times F_{t}\left(\xi_{t}\right)$. Then, the Copula density function is a constant value $c_{t}\left(G_{t}\left(\eta_{t}\right), F_{t}\left(\xi_{t}\right)\right)=1$. The optimal order quantity of the retailer at wholesale price $w$ is given by Corollary 2 .

Corollary 2. When the price and the demand in each level are independent of each other, the retailer's optimal order quantity satisfies the following equation:

$$
\begin{aligned}
& E\left(\eta_{1}\right)-E\left(\eta_{1}\right) F_{1}\left(Q^{*}\right)+E\left(\eta_{2}\right) F_{1}\left(Q^{*}\right) \\
& \quad-\left[E\left(\eta_{2}\right)+c_{h}\right] \int_{0}^{Q^{*}} F_{2}\left(Q^{*}-\xi_{1}\right) f_{1}\left(\xi_{1}\right) \mathrm{d} \xi_{1}=w .
\end{aligned}
$$

In a second special case where the retailer does not take a price discount strategy and any products unsold by the end of the normal price period are to be disposed of, the optimal order quantity is obtained by simplifying (13) (see Corollary 3).

Corollary 3. Take $\eta_{2}=-c_{h}$ and assume $\xi_{2}$ no longer exists, and the optimal two-level price-fluctuation ordering problem is reduced to the ordering problem at normal price, where the retailer's optimal ordering quantity satisfies the following equation:

$$
E\left(\eta_{1}\right)-\int_{0}^{+\infty} \int_{0}^{Q^{*}}\left(c_{h}+\eta_{1}\right) H_{1}\left(\eta_{1}, Q^{*}\right) g_{1}\left(\eta_{1}\right) \mathrm{d} \xi_{1} \mathrm{~d} \eta_{1}=w
$$

The proof is similar to that for Theorem 1 .
In a third special case where the retail price is set at a deterministic value and does not affect demand, then Corollary 3 becomes the result of traditional deterministic price ordering models, in $[27,28]$.

\section{Approximate Solution of Optimal Ordering Strategy for the Discrete Model}

In practice, the retail price and the demand fluctuate at finite discrete points and the supplier provides a limited number of wholesale prices, so (P3) is transformed in this section into a discrete decision model. Assuming the maximum possible wholesale price is $\bar{w}$, then the wholesale price set of the supplier is denoted by $W=\left[c_{0}, \bar{w}\right]$. Products are sold at fluctuant prices, limited, and dissected, with all possible prices and demands:

$$
\begin{aligned}
& \left(\eta_{1 i_{1}}, \xi_{1 j_{1}}\right), \quad i_{1}=1,2, \ldots, r_{1}, j_{1}=1,2, \ldots, m_{1}, \\
& \left(\eta_{2 i_{2}}, \xi_{2 j_{2}}\right), \quad i_{2}=1,2, \ldots, r_{2}, j_{2}=1,2, \ldots, m_{2} .
\end{aligned}
$$

Denote the joint probability of the discrete prices and demands at each level as $P\left(\eta=\eta_{1 i_{1}}, \xi=\xi_{1 j_{1}}\right)=P_{1 i_{1} j_{1}}$, $P\left(\eta=\eta_{2 i_{2}}, \xi=\xi_{2 j_{2}}\right)=P_{2 i_{2} j_{2}}, P_{1 j_{1}}$ as the marginal distribution of the demand at the normal level and $P_{2 j_{2}}$ as the marginal distribution of the demand at the discount level. We denote $\bar{j}_{1}$ as $\bar{j}_{1} \in\left\{j_{1} \mid j_{1}=1,2, \ldots, m_{1}\right\}$ satisfying $\xi_{1 \bar{j}_{1}} \leq Q$ and $\xi_{1\left(\bar{j}_{1}+1\right)}>Q$ with $\xi_{1 j_{1}}$ flowing from small to large, $\bar{j}_{2}$ as $\bar{j}_{2} \in\left\{j_{2}, j_{2}=1,2, \ldots, m_{2}\right\} \quad$ satisfying $\xi_{2 \bar{j}_{2}} \leq Q-\xi_{1 j_{1}}$ and $\xi_{2\left(\bar{j}_{2}+1\right)}>Q-\xi_{1 j_{1}}$ with $\xi_{2 j_{2}}$ flowing from small to large at discount level, and $\xi_{2} \bar{j}_{2}$ as the threshold where the unsold volume after the normal price meets the demand at the discount level.

The supplier's profit is denoted by $\bar{G}_{s}(\mathrm{Q}, w)$, and (P4), the discrete decision model, is obtained: 
(P4)

$$
\begin{array}{ll}
\max & \bar{G}_{s}(Q, w(Q))=\left(w(Q)-c_{0}\right) Q \\
\text { s.t. } & \left\{\begin{array}{l}
w(Q)=\sum_{i_{1}=1}^{r_{1}} \sum_{j_{1}=1}^{m_{1}} \eta_{1 i_{1}} P_{1 i_{1} j_{1}}-\sum_{i_{1}=1}^{r_{1}} \sum_{j_{1}=1}^{\overline{j_{1}}} \eta_{1 i_{1}} P_{1 i_{1} j_{1}}+\sum_{j_{1}=1}^{\overline{j_{1}}} \sum_{i_{2}=1}^{r_{2}} \sum_{j_{2}=1}^{m_{2}} \eta_{2 i_{2}} P_{2 i_{2} j_{2}} P_{1 j_{1}}-\sum_{j=1}^{\overline{j_{1}}} \sum_{i_{2}=1}^{r_{2}} \sum_{j_{2}=1}^{\overline{j_{2}}}\left(\eta_{2 i_{2}}+c_{h}\right) P_{2 i_{2} j_{2}} P_{1 j_{1}}, \\
w(Q) \in W .
\end{array}\right.
\end{array}
$$

From Corollary 1, we have $Q^{\prime}(w)<0$; hence, $w$ is inversely proportional to $Q$. Take $Q=0$, $w(Q)=\sum_{i_{1}=1}^{r_{1}} \sum_{j_{1}=1}^{m_{1}} \eta_{1 i_{1}} P_{1 i_{1} j_{1}}>c_{0}$. Since $w$ decreases with the increase of $Q$, we can get a $w(Q)$ that $w(Q) \in\left[c_{0}, \bar{w}\right]$ by searching incrementally for $Q$ in a certain range. By solving (P4), the approximate optimal order quantity under discrete prices and demands is obtained. In the discrete model, denote $\bar{Q}^{*}$ as the approximate optimal order quantity and $\bar{G}_{s}^{*}, \bar{G}_{\mathrm{re}}^{*}$, and $\bar{G}^{*}$ as the maximum profit or the expected profit of the supplier, the retailer, and the whole supply chain.

In practical application, with the actual data, Monte Carlo method is used to generate enough number pairs of price and demand that meet the corresponding Copula relationship, and then, the approximate optimal order quantity is calculated through solving (P4). Next, we discuss how to generate number pairs of random price and demand through historical data and give an algorithm (called Algorithm 1) to calculate the approximate optimal order quantity.

Theorem 2. The supplier's profit sequence $\left\{\bar{G}_{s}\left(\bar{Q}_{k}^{*}, w\left(\bar{Q}_{k}^{*}\right)\right)\right\}$ and the approximate optimal order quantity sequence $\left\{\bar{Q}_{k}^{*}\right\}$ obtained by Algorithm 1 are convergent. The algorithm terminates finitely.

Proof of Theorem 2. According to Step 8, the supplier profit sequence $\left\{\bar{G}_{s}\left(\bar{Q}_{k}^{*}, w\left(\bar{Q}_{k}^{*}\right)\right)\right\}$ is obviously monotonically increasing with $k$. Since $Q_{i k}$ is bounded, the sequence $\left\{\bar{G}_{s}\left(\bar{Q}_{k}^{*}, w\left(\bar{Q}_{k}^{*}\right)\right)\right\}$ is convergent to a finite value. Therefore, $\left|\bar{G}_{s}\left(\bar{Q}_{k-1}^{*}, w\left(\bar{Q}_{k-1}^{*}\right)\right)-\bar{G}_{s}\left(\bar{Q}_{k}^{*}, w\left(\bar{Q}_{k}^{*}\right)\right)\right|$ converges to $\varepsilon$ in finite number of steps.

According to Theorem 1 and Theorem 2, when $N_{k}$ is large enough, an approximate optimal order quantity is obtained through Algorithm 1.

\section{Numerical Experiments}

5.1. Approximate Solution of Optimal Order Quantity in Two-Level Price-Fluctuation Sales. The sales of boxed Dongkui waxberry (a kind of waxberry commonly available in June and/or July) of a retailer in a fresh agricultural product supply chain, including both online and offline in Xihu District, Hangzhou, are surveyed. Dongkui waxberry is sold of the same quality in a package of $500 \mathrm{~g}$ per box where the retailer adopts a normal price-fluctuation strategy and/or a $50 \%$ discount price-fluctuation strategy within a sales cycle.

By goodness-of-fit test, it is found that the price and the demand meet Gauss Copula correlation, which uses linear correlation coefficient $\rho$ to measure the correlation between two random variables. If $\rho=0$, the two random variables are independent; if $\rho=1$, the two variables are collinearly positively correlated; on the contrary, $\rho=-1$ means that the two variables are collinearly negatively correlated [31]. Through historical data, set $\rho=-0.6$.

Through statistics, the total demand volume at each price level in a sales cycle is obtained with the highest and lowest volume of 2191 boxes and 1821 boxes at the normal level, and 3350 boxes and 2779 boxes at the discount level, while the retail prices fluctuate in the range of $[91,99]$ (CNY per box) at the normal level and [41, 49] (CNY per box) at the discount level. It is found that the retail price as well as the sales volume approximately obeys normal distribution at each price level. With the help of MATLAB and through Algorithm 1 proposed in the previous section, we simulate and obtain 5000 number pairs of price and demand at each price level and enough data are obtained for analysis. It is obtained that the sales volume at each price level for every ordering obeys normal distribution with $\mu_{\xi_{1}}=1996$, $\sigma_{\xi_{1}}=197.5, \mu_{\xi_{2}}=3002$, and $\sigma_{\xi_{2}}=299.5$; and the price approximately obeys normal distribution with $\mu_{\eta_{1}}=89.7$, $\sigma_{\eta_{1}}=9.21, \mu_{\eta_{2}}=45.2$, and $\sigma_{\eta_{2}}=4.47$ accordingly. By investigation, set the unit disposal cost 5 (CNY per box), the supplier's unit production cost 10 (CNY per box), and the set of the wholesale price $W=\{w, w \in[10,40]\}$ (CNY per box).

The approximate optimal order quantity and the corresponding maximum profit of the supplier are calculated as shown in Figure 2.

Figure 2 confirms the conclusion of Corollary 1 that the optimal order quantity decreases with the increase of the wholesale price $w$. When the wholesale price $w^{*}=38 \mathrm{CNY}$ and the approximate optimal order quantity $\bar{Q}^{*}=4155$ boxes, the maximum profit of the supplier is $116340 \mathrm{CNY}$. Therefore, $\left(w^{*}, \bar{Q}^{*}\right)=(38,4155)$ is the approximate optimal strategy for two-level supply chain price-fluctuation sales.

5.2. Impact of Demand Allocations on the Optimal Order Quantity. In this section, the impact of demand allocations on the optimal order quantity is discussed. Because market capacity is limited, it is reasonable to assume that the total demand is fixed throughout a sales cycle and the demand at the normal price level may or may not be higher than the one at the discount price level due to customers' preference. Therefore, in this section, we examine the impact of demand allocations on optimal order quantity in three demand allocations where the total demand remains constant. Set the mean value of the total demand at 5000 and the ratio of the mean value of the demand at the normal price $\mu_{\xi}$ to that at the discount price $\mu_{\xi_{2}}$ at $1: 4,2: 3$, and $3.5: 1.5$ in three allocations. For ease of comparison, we increase or decrease 
Step 1: select suitable Copula functions according to the characteristics of price and demand fluctuation at each price level. First based on the experience, then the goodness-of-fit test is carried out. Specific Copula functions are selected as per [29, 30]. And the parameters of the selected Copula functions are set through historical data.

Step 2: determine the marginal distributions of price and demand at each price level $G_{t}\left(\eta_{t}\right), F_{t}\left(\xi_{t}\right), t=1,2$ with the related parameters estimated through the historical data.

Step 3: generate two pairs of random variables $\left(u_{11}, u_{12}\right)$ and $\left(u_{21}, u_{22}\right)$, with marginal distributions satisfying uniform distribution in $[0,1]$ and the correlation in each pair satisfying the selected Copula function.

Step 4: number pairs of random price and demand at each level $\left(\eta_{t}, \xi_{t}\right), t=1,2$ are obtained by inverse transformation: $\eta_{1}=G_{1}^{-1}\left(u_{11}\right), \xi_{1}=F_{1}^{-1}\left(u_{12}\right), \eta_{2}=G_{2}^{-1}\left(u_{21}\right), \xi_{2}=F_{2}^{-1}\left(u_{22}\right)$.

Repeat Step 3-Step 4, enough number pairs of random price and demand are obtained for both price levels, which satisfy the given marginal distributions and Copula functions.

Step 5: initialize parameters $c_{0}, c_{h}, \bar{w}, k=1, \bar{G}_{s}\left(\bar{Q}_{0}^{*}, w\left(\bar{Q}_{0}^{*}\right)\right)=0, N_{k}>1, b>1, \varepsilon>0$, and the wholesale price set $W=\left[c_{0}, \bar{w}\right]$. According to the generated discrete data of price and demand, the joint probability distributions of price and demand at two price levels are calculated, denoted by $P_{t}, t=1,2$, then the marginal distribution of demand $P_{\xi_{t}}, t=1,2$ at each level is obtained. The statistic demand intervals at the normal and the discount levels are $\left[\min { }_{-} Q_{1}, \max _{-} Q_{1}\right]$ and $\left[\min _{-} Q_{2}, \max _{-} Q_{2}\right]$. Then, the order quantity interval is determined, denoted by $\left[\min _{-} Q, \max _{-} Q\right]$, where $\min { }_{-} Q=\min \left\{\min { }_{-} Q_{1}, \min _{-} Q_{2}\right\}$ and

$\max \_Q=\max Q_{1}+\max _{-} Q_{2}$.

Step 6: divide the order quantity interval [min $\left.\_Q, \max _{-} Q\right]$ into $N_{k}-1$ equal parts, where $\Delta Q_{k}=\left[\max _{-} Q-\min _{-} Q\right] /\left(N_{k}+1\right)$. Let $Q_{i k}=\min _{-} Q+i \Delta Q_{k}, i=0,1,2, \ldots, N_{k}$.

Step 7: calculate corresponding $w\left(Q_{i k}\right)$ according to the discrete model (P4): $w\left(Q_{i k}\right)=\sum_{i_{1}=1}^{r_{1}} \sum_{j_{1}=1}^{m_{1}} \eta_{1 i_{1}} P_{1 i_{1} j_{1}}-$ $\sum_{i_{1}=1}^{r_{1}} \sum_{j_{1}=1}^{\bar{j}_{1}} \eta_{1 i_{1}} P_{1 i_{1} j_{1}} \sum_{j_{1}=1}^{\bar{j}_{1}} \sum_{i_{2}=1}^{r_{2}} \sum_{j_{2}=1}^{m_{2}} \eta_{2 i_{2}} P_{2 i_{2} j_{2}} P_{1 j_{1}}-\sum_{j=1}^{\bar{j}_{1}} \sum_{i_{2}=1}^{r_{2}} \sum_{j_{2}=1}^{\overline{j_{2}}}\left(\eta_{2 i_{2}}+c_{h}\right) P_{2 i_{2} j_{2}} P_{1 j_{1}}$.

Take indicator set: $I_{k}=\left\{i \mid w\left(Q_{i k}\right) \in W, i=0,1,2, \ldots, N_{k}\right\}$.

Step 8: obtain the profit set of the supplier $\left\{\bar{G}_{s}\left(Q_{i k}, w\left(Q_{i k}\right)\right), i \in I_{k}\right\}$ satisfying indicator set $I_{k}$ and calculate the approximate optimal order quantity which maximizes the profit of the supplier, i.e., $\bar{Q}_{k}^{*}=\arg \max _{Q_{i k}}\left\{\bar{G}_{s}\left(\bar{Q}_{k-1}^{*}, w\left(\bar{Q}_{k-1}^{*}\right)\right), \bar{G}_{s}\left(Q_{i k}, w\left(Q_{i k}\right)\right), i \in I_{k}\right\}$, and the maximum profit of the supplier $\bar{G}_{s}\left(\bar{Q}_{k}^{*}, w\left(\bar{Q}_{k}^{*}\right)\right)$ is calculated.

Step 9: if $\left|\bar{G}_{s}\left(\bar{Q}_{k-1}^{*}, w\left(\bar{Q}_{k-1}^{*}\right)\right)-\bar{G}_{s}\left(\bar{Q}_{k}^{*}, w\left(\bar{Q}_{k}^{*}\right)\right)\right|<\varepsilon$, the algorithm terminates. The approximate optimal order quantity is $\bar{Q}_{k}^{*}$, and the corresponding wholesale price is $w\left(\bar{Q}_{k}^{*}\right)$; the supplier's profit is $\bar{G}_{s}\left(\bar{Q}_{k}^{*}, w\left(\bar{Q}_{k}^{*}\right)\right)$. Otherwise, let $N_{k+1}=b N_{k}, k:=k+1$, go to Step 6 .

\section{Algorithm 1}

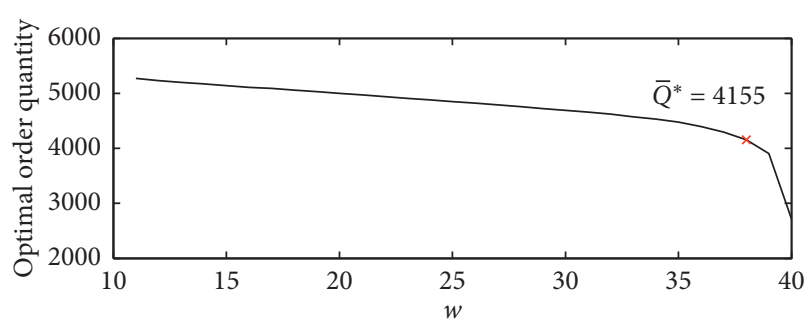

(a)

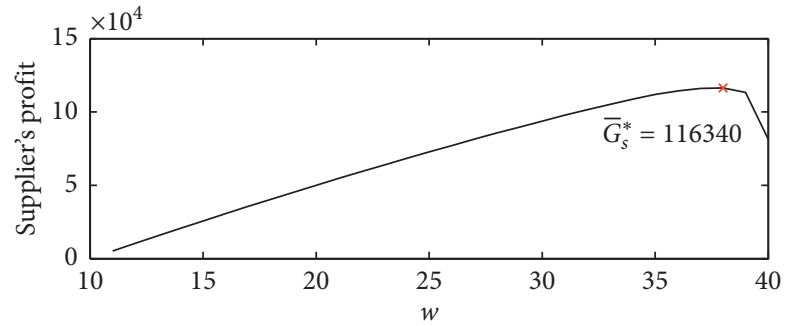

(b)

FIGURE 2: Optimal order quantity and supplier's profit at wholesale prices.

the standard deviation of the demand proportionally to the change of the mean value. Other parameters are the same as the ones in Section 5.1. The results are shown in Table 3.

When the ratio of the demand at the normal level increases, the optimal order quantity increases, and the profits of the retailer and the supplier increase substantially. Therefore, when products are sold in two-level price-fluctuation sales, more should be sold at the normal price level instead of later promoting through discount, which can greatly increase the profits of the members of the supply chain.

5.3. Impact of Price Fluctuation and Demand Uncertainty on the Optimal Order Quantity. It is known to all that the uncertainty of market demand, as well as the price fluctuation, greatly affects the profits of the members in the supply chain. This section focuses on the impact of price fluctuation as well as the impact of demand uncertainty on the ordering strategy and discusses how they affect the profits of each member in the supply chain in two-level price-fluctuation sales. Here, fluctuation and the uncertainty are both measured by the percentage of standard deviation from the mean value. The results are shown in Figures 3 and 4 .

Figure 3 indicates that when the retail price fluctuation is large, the optimal order quantity decreases. When the retail price fluctuates within a certain range (this experiment shows that the percentage of the standard deviation from the mean value equals 20\%), the retailer's profit decreases and the supplier's profit increases as the increase in price fluctuation. However, when the increase of price fluctuation is 
TABle 3: Optimal quantities in demand allocations and profits of supply chain members.

\begin{tabular}{lccccr}
\hline$\mu_{\xi_{1}}: \mu_{\xi_{2}}$ & $w^{*}$ & $\overline{\mathrm{Q}}^{*}$ & $\overline{\mathrm{G}}_{\mathrm{re}}^{*}$ & $\overline{\mathrm{G}}_{s}^{*}$ & $\overline{\mathrm{G}}^{*}$ \\
\hline $1: 4$ & 38 & 4060 & 62851.4 & 113680 & 176531.7 \\
$2: 3$ & 38 & 4155 & 88536.8 & 116340 & 204876.8 \\
$3.5: 1.5$ & 40 & 4185 & 165715.9 & 125550 & 291265.9 \\
\hline
\end{tabular}

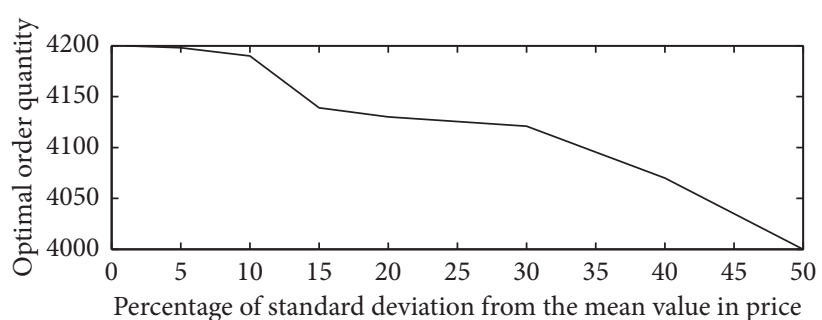

(a)

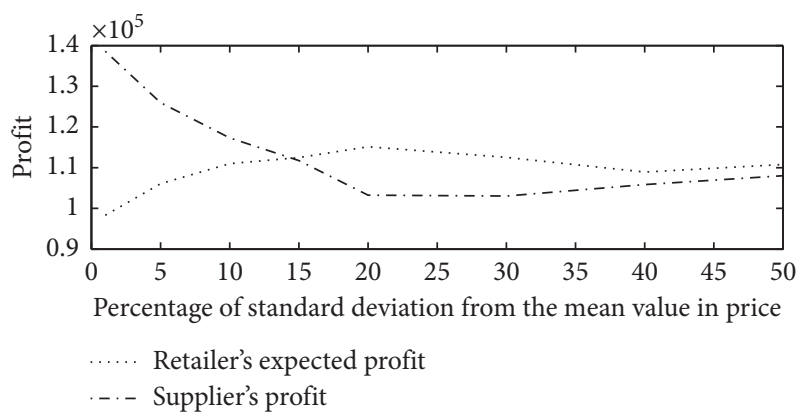

(b)

Figure 3: The impact of price fluctuation on the optimal order quantity.

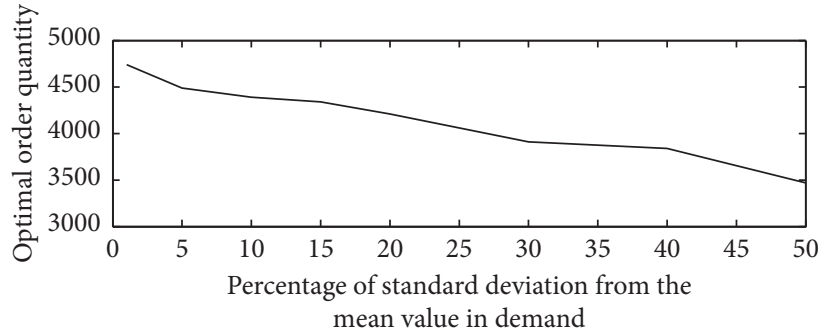

mean value in demand

(a)

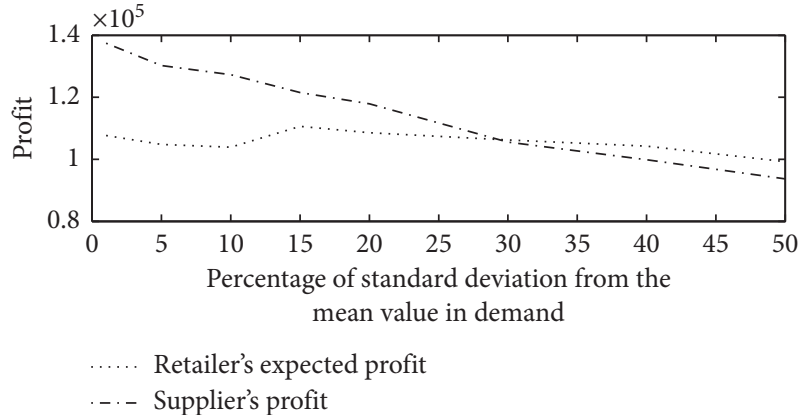

(b)

Figure 4: The impact of demand uncertainty on the optimal order quantity.

over the threshold-the abovementioned range, the impacts of price fluctuation on both the retailer and the supplier are almost the same.

Figure 4 shows that the demand uncertainty is inversely proportional to the optimal order quantity. The higher the demand uncertainty, the lower the optimal order quantity. The increase in demand uncertainty reduces the profits of the retailer and supplier.

Therefore, members in the supply chain need to fully predict the fluctuation of both price and demand before making an ordering strategy. When the fluctuation of retail price and demand is large, retailers should reduce the order quantity appropriately so as to maximize profits.

5.4. Impact of Correlation on the Optimal Order Quantity in Different Copula Markets. Different products have different price-demand correlations. Generally, price is inversely proportional to demand, so in this section, a negative correlation between price and demand is taken and its impacts on the ordering strategy under different Copula Markets are discussed. Gauss Copula, t-Copula [32], and Frank Copula [33] are used to describe different Copula markets, in which Gaussian Copula and t-Copula describe the correlation between price and demand by linear correlation coefficient and Frank Copula characterizes them by rank correlation coefficient. The relationships between correlation and optimal order quantity under different Copula markets are calculated (see Figures 5 and 6).

Figure 5 shows that the correlation between price and demand has different effects on the ordering strategy in different Copula markets. In Gauss Copula and t-Copula markets, the optimal order quantity decreases as the correlation between price and demand increases. Under Frank function, the impact is irregular. Figure 6 shows that the profits of the retailer in three Copula markets decrease with the increase in correlation. In Gauss Copula and t-Copula markets, supplier's profits increase with the increase in correlation while in Frank Copula market, the change in supplier's profit is not obvious. Thus, in two-level price- 


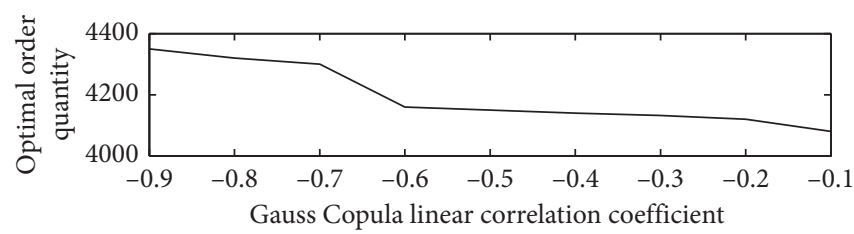

(a)

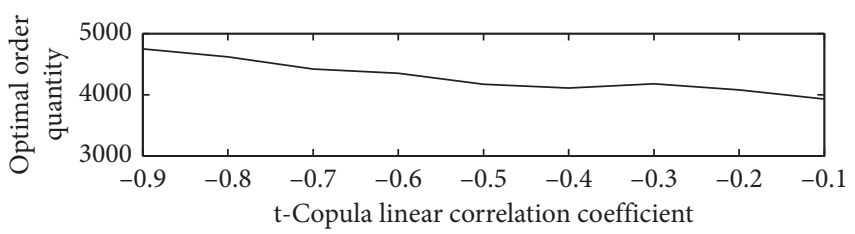

(b)

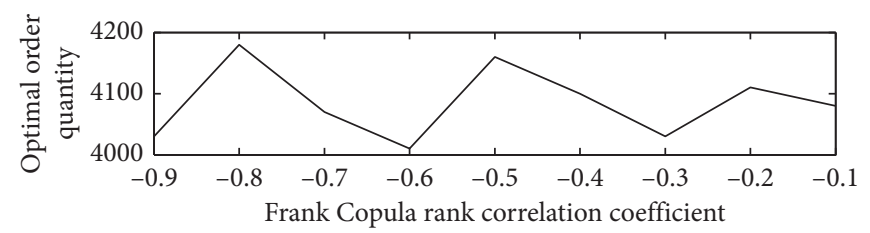

(c)

FIGURE 5: The impact of correlation on ordering strategy in different Copula markets.

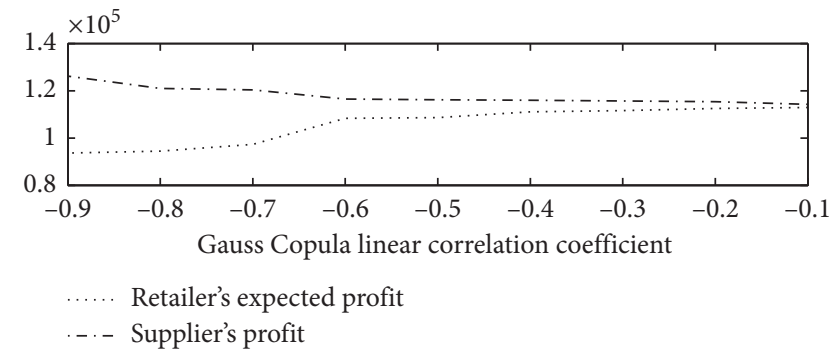

(a)

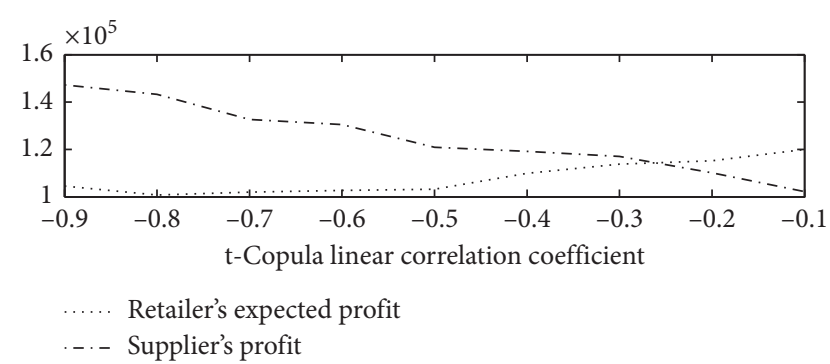

(b)

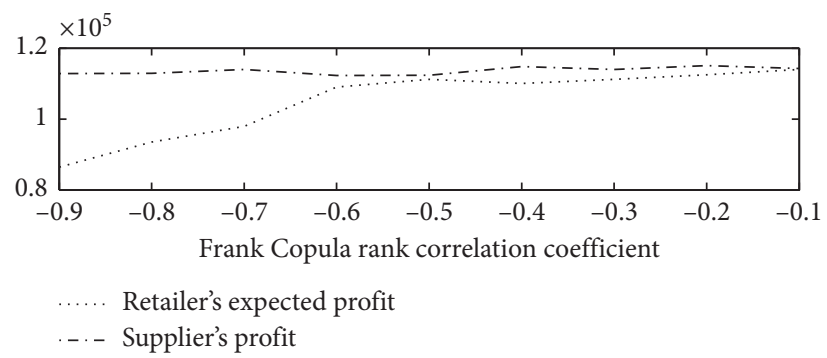

(c)

Figure 6: The impact of correlation on each profit in different Copula markets.

fluctuation sales, the correlation between price and demand has different effects on members in the supply chain. If the demand is sensitive to price, the retailer's profit will be much less than the supplier's while if the demand is not sensitive, the retailer's and the supplier's profits will tend to be the same.

Through the numerical simulations, it can be found that the supply chain needs to fully consider the price fluctuations and the demand uncertainties when making ordering decisions. And some detailed management suggestions are obtained:

(1) If the price fluctuation increases, the decisionmaker should appropriately reduce the order quantity, because in such an occasion, more profits will go to the retailer as compared to the supplier when the price fluctuates within a certain range, and the retailer is likely to gain higher profits. But this requires the attention of the supplier; (2) with the increase in demand uncertainty, the decision-maker should reduce the order quantity, while the profits of both the supplier and the retailer would decrease as well. Therefore, both the supplier and the retailer should provide high-quality products and services, so as to maintain the stability of the demand as much as possible; (3) since the order quantity and the profits of both the supplier and the retailer increase with the increase of the demand proportion at the first level, the supply chain members should do their utmost to sell more products at the first level, so as to obtain higher profits; (4) supply chain members need to pay attention to the correlation between the price and the demand since it has great effects on the optimal ordering strategy. 


\section{Conclusions and Possible Extensions}

The optimal ordering problem of the supply chain in two-level price-fluctuation sales is studied here. A bilevel programming model is established to maximize the expected profit of the supplier and the retailer with the optimal order quantity deduced by transforming the model into a single-level programming problem where Copula function is used to establish the joint distribution by connecting the marginal probability distributions of price and demand. Then, a discrete model is established when demand and price are finite discrete data in the real world with an algorithm for approximate optimal order quantity proposed, and the convergence of the algorithm proved.

Unlike many previous studies on supply chain ordering problem where the retail price is always set to be fixed, the paper tries to find an appropriate ordering decision from another point of view: price fluctuation under retailer's twolevel price strategy-a critical uncertainty in decision making. Since two-level price-fluctuation sales are common, this study has practical significance.

Via numerical experiments, the followings are observed:

(i) Supply chain members should try their best to sale more products at the normal price level, rather than discount, so as to increase profits.

(ii) The optimal order quantity decreases with the increase of price fluctuation as well as the increase of demand uncertainty.

(iii) When the retail price fluctuates within a certain range, the retailer's profit decreases and the supplier's profit increases with the increase of price fluctuation as well as the increase of demand uncertainty.

(iv) In different Copula markets, the correlation between price and demand has different effects on the optimal order quantity. In Gauss Copula and $\mathrm{t}$-Copula markets, the order quantity decreases with the increase in the correlation, while in Frank market, the correlation does not show any obvious corresponding law.

Due to the complexity of ordering problems in the supply chain facing price fluctuation, our studies are limited to the two-echelon supply chain including only one supplier and one retailer, and the two-level price strategies are considered. The logic further researches may include the following:

(i) The ordering problem with retail price fluctuation in multiechelon supply chain

(ii) The supply chain ordering problem facing multilevel price-fluctuation sales

(iii) Different price-demand distributions should be taken into consideration

(iv) Different objective functions should be studied

(v) Value losses in purchases and sales, which is quite common for some products in the business world, should be taken into consideration in the future models
This paper provides practical guidance for supply chain members facing two-level fluctuating price sales. As there is no relevant research on the supply chain ordering problem of two-level price-fluctuation sales while price-fluctuation sales are ubiquitous in practice, this paper has both theoretical and practical significance.

\section{Data Availability}

The data used to support the findings of this study are included within the article.

\section{Conflicts of Interest}

The authors declare that they have no conflicts of interest.

\section{Acknowledgments}

This work was supported by the National Natural Science Foundation of China (Grant no. 11871434) and the Natural Science Foundation of Zhejiang Province (Grant no. LY18A010031).

\section{References}

[1] Y. Gorodnichenko and O. Talavera, "Price setting in online markets: basic facts, international comparisons, and crossborder Integration," American Economic Review, vol. 107, no. 1, pp. 249-282, 2017.

[2] R. Chenavaz, J. Drouard, O. R. Escobar, and B. Karoubi, "Convenience pricing in online retailing: evidence from Amazon.com," Economic Modelling, vol. 70, pp. 127-139, 2018.

[3] Profitero. Avoiding a race to the bottom, http://insights. profitero.com/rs/476-BCC-343/images/Profitero_Avoidinga-Race-to-the-Bottom.pdf.

[4] S. Islam and C. Colonescu, "Data on retail price differential between organic and conventional foods," Data in Brief, vol. 27, 2019.

[5] C. J. Yu and B. W. Gould, "Market power and farm-retail price transmission: the case of US fluid milk markets," Agribusiness, vol. 35, no. 4, pp. 537-555, 2019.

[6] M. Khouja, "The newsboy problem under progressive multiple discounts," European Journal of Operational Research, vol. 84, no. 2, pp. 458-466, 1995.

[7] Z. Pang, F. Y. Chen, and Y. Feng, "Technical note-a note on the structure of joint inventory-pricing control with leadtimes," Operations Research, vol. 60, no. 3, pp. 581-587, 2012.

[8] A. Federgruen and A. Heching, "Combined pricing and inventory control under uncertainty," Operations Research, vol. 47, no. 3, pp. 454-475, 1999.

[9] M. Khouja, S. Park, J. Zhou et al., "A free gift card alternative to price discounts in the newsvendor problem," Omega, vol. 41, no. 4, pp. 665-678, 2013.

[10] T. Ye and H. Sun, "Price-setting newsvendor with strategic consumers," Omega, vol. 63, pp. 103-110, 2016.

[11] Y. Mu, Z. Meng, R. Shen, G. Zhou, L. Xu, and M. Zheng, "Optimal ordering strategy for goods at multiple retail prices under simultaneous sales," Discrete Dynamics in Nature and Society, vol. 2019, Article ID 9627469, 14 pages, 2019.

[12] O. Jadidi, S. Taghipour, and S. Zolfaghari, "A two-price policy for a newsvendor product supply chain with time and price 
sensitive demand," European Journal of Operational Research, vol. 253, no. 1, pp. 132-143, 2016.

[13] N. H. Shah, G. A. Widyadana, and H. M. Wee, "Stackelberg game for two-level supply chain with price markdown option," International Journal of Computer Mathematics, vol. 91, no. 5, pp. 1054-1060, 2014.

[14] G. A. Widyadana and H. M. Wee, "Supply chain retailer price markdown policy for deteriorating inventory," in Proceedings of the 2008 4th IEEE International Conference on Management of Innovation and Technology, pp. 1401-1406, IEEE, Bangkok, Thailand, 2008.

[15] B. B. Venegas and J. A. Ventura, "A two-stage supply chain coordination mechanism considering price sensitive demand and quantity discounts," European Journal of Operational Research, vol. 264, no. 2, pp. 524-533, 2018.

[16] N. C. Petruzzi and M. Dada, "Pricing and the newsvendor problem: a review with extensions," Operations Research, vol. 47, no. 2, pp. 183-194, 1999.

[17] L. Yao, Y. F. Chen, and H. Yan, "The newsvendor problem with pricing: Extensions," International Journal of Management Science and Engineering Management, vol. 1, no. 1, pp. 3-16, 2006.

[18] C. S. Tapiero, "Orders and inventory commodities with price and demand uncertainty in complete markets," International Journal of Production Economics, vol. 115, no. 1, pp. 12-18, 2008.

[19] C. S. Tapiero and K. Kogan, "Risk-averse order policies with random prices in complete market and retailers' private information," European Journal of Operational Research, vol. 196, no. 2, pp. 594-599, 2009.

[20] M. Sklar, Fonctions de Repartition an Dimensions et LeursMarges, vol. 8, Paris Institute of Statistics, Paris, France.

[21] L. Hu, "Dependence patterns across financial markets: a mixed copula approach," Applied Financial Economics, vol. 16, no. 10, pp. 717-729, 2006.

[22] C. Bruneau, A. Flageollet, and Z. Peng, "Economic and financial risk factors, copula dependence and risk sensitivity of large multi-asset class portfolios," Annals of Operations Research, vol. 284, no. 1, pp. 165-197, 2020.

[23] M. L. Xu and Z. Li, "Newsvendor decision based on CopulaCVaR with price-dependent demand," Control \& Decision, vol. 29, no. 6, pp. 1083-1090, 2014.

[24] H. Sun and S. M. Gilbert, "Retail price competition with product fit uncertainty and assortment selection," Production and Operations Management, vol. 28, no. 7, pp. 1658-1673, 2019.

[25] Y. Z. Hou, G. X. Dai, and Q. D. Yu, "The application of two ordering opportunities in single-period products of reverse supply chain management," System Engineering Theory and Practice, vol. 25, no. 11, pp. 35-40, 2005.

[26] H. L. Lau and H. S. Lau, "Decision models for single-period products with two ordering opportunities," International Journal of Production Economics, vol. 55, no. 1, pp. 57-70, 1998.

[27] M. Khouja, "The single-period (news-vendor) problem: literature review and suggestions for future research," Omega, vol. 27, no. 5, pp. 537-553, 1999.

[28] Y. Qin, R. Wang, A. J. Vakharia et al., "The newsvendor problem: review and directions for future research," European Journal of Operational Research, vol. 213, no. 2, pp. 361-374, 2011.

[29] D. X. Li, "On default correlation," The Journal of Fixed Income, vol. 9, no. 4, pp. 43-54, 2000.
[30] X. Ren and S. Zhang, "Copula function selection criterion based on nonparametric kernel density estimation," Journal of System Engineering, vol. 25, no. 1, pp. 36-42, 2010.

[31] L. Andersen and J. Sidenius, "Extensions to the Gaussian Copula: random recovery and random factor loadings," Journal of Credit Risk, vol. 1, no. 1, 2005.

[32] T. Schmidt, Coping with Copulas in "Copulas: From Theory to Applications in Finance", Risk Books, Incisive Financial Publishing, London, UK, 2006.

[33] M. J. Frank, "On the simultaneous associativity of $F(x, y)$ and $x+y-F(x, y)$," Aequationes Mathematicae, vol. 18, no. 1-2, pp. 266-267, 1978. 